Authors' accepted version (i.e., final draft post-refereeing)

To be published as:

Van der Linden, V., Dong, H., Heylighen, A., Tracing architects' fragile knowing about users in the sociomaterial environment of design, Design Studies

Please refer to the publisher's final version. 


\title{
Tracing architects' fragile knowing about users in the socio-material environment of design
}

\author{
Valerie van der Linden and Ann Heyligen \\ Dept. of Architecture, Research[x]Design, KU Leuven, Kasteelpark Arenberg 1/2431, 3001 Leuven, \\ Belgium \\ Hua Dong \\ Loughborough School of Design, Loughborough University, Leicestershire, UK
}

\begin{abstract}
The increasing complexity of architectural practice presents a challenge to transferring knowledge from use to design contexts, leaving attending to user experience an implicit design dimension. An ethnographic study in three firms sheds light on how knowledge about user experience - unpacked into facets of perception, activity and meaning - is embedded in architectural practice. It offers insight into the fragile nature of knowledge about user experience, as it is largely contingent, implicit and essentially person-bound. Mapping how this knowledge is mediated by the socio-material environment of design identifies challenges to knowledge transfer as well as leads. It highlights the coupling of narratives and materials as a design-oriented way to unlock embodied knowledge, so as to support architects in addressing user experience.

Keywords:

architectural design; design knowledge; design practice; experience; user centred design

Corresponding author:

Valerie van der Linden valerie.vanderlinden@kuleuven.be
\end{abstract}




\section{Highlights}

- Architects' knowing about users is largely contingent, implicit and person-bound.

- User experience in architecture entails how a space feels, works and what it means.

- The socio-material context of design mediates knowledge about user experience.

- The complexity of design processes challenges knowledge transfer.

- Materialising narratives is a design-oriented way to support architects' knowing. 


\title{
Tracing architects' fragile knowing about users in the socio-material environment of design
}

\begin{abstract}
The increasing complexity of architectural practice presents a challenge to transferring knowledge from use to design contexts, leaving attending to user experience an implicit design dimension. An ethnographic study in three firms sheds light on how knowledge about user experience - unpacked into facets of perception, activity and meaning - is embedded in architectural practice. It offers insight into the fragile nature of knowledge about user experience, as it is largely contingent, implicit and essentially person-bound. Mapping how this knowledge is mediated by the socio-material environment of design identifies challenges to knowledge transfer as well as leads. It highlights the coupling of narratives and materials as a design-oriented way to unlock embodied knowledge, so as to support architects in addressing user experience.
\end{abstract}

Keywords: architectural design; design knowledge; design practice; experience; user centred design

The increasing complexity in architectural design processes presents a challenge for architects to take into account users' perspectives. Although architects acknowledge the lack of insight into 'other' people's perspectives mainly in unfamiliar use conditions or contexts (Van der Linden, Dong, \& Heylighen, 2016b), their distance from users is often found in architectural practice. With clients often not being those using the building (Zeisel, 1984, pp. 34-35) and a growing diversity in terms of the stakeholders involved (e.g., in procurement) (Newcombe, 2003), the parties involved in the decision-making may have limited knowledge about or access to users' perspectives. This situation challenges planning for user needs and understanding the effects of decisions on users, which possibly compromises the design's appropriateness.

These observations point to a need to inform architectural practice about user experience. This need seems to be addressed unsuccessfully by traditional outcomes of research about users. They find little uptake in design, as they seem incompatible with architects' 'designerly ways of knowing' (Cross, 1982), in terms of both content and form (cf. Diaz Moore \& Geboy, 2010; Kirkeby, 2009). Attending to user experience remains an implicit dimension of the design process, associated with architects' expertise (Van der Linden, Dong, \& Heylighen, 2018; Oygür, 2014). When explaining what guided their design decisions concerning user experience, architects often refer to their 'intuition'. 
This seemed to be a catch-all term that, when remaining unpacked, gives little insight into what goes on in architects' knowing about users. ${ }^{1}$

The starting point of our study is that understanding the mechanisms of architectural practice can be a key to supporting more effective knowledge transfer from use to design contexts. Instead of understanding 'to inform' in a static way, as making sources available, we adopt a more ecological understanding and consider the practice in which knowledge is adopted. This means taking into account the complex reality of architectural practice: a dynamic network of persons and materials, mediating knowledge between the use context and the design context. This aligns with understandings of design cognition as situated in and distributed over a socio-material environment (Le Dantec, 2010; Yaneva, 2009).

Starting from the question what 'designerly ways of knowing' entail with regard to user experience, we empirically explore (a) how architects know about (different facets of) user experience, and (b) how this knowledge is mediated in the socio-material environment of design practice. Insights are expected to help identify specific leads to supporting architects in addressing user experience, which is considered essential in promoting more supportive environments. Given the focus on the rich context of daily architectural practice, we conducted an ethnographic field study in three Belgian architecture firms in order to understand architects' ways of working.

This article is organised as follows. First we introduce related literature on informing design practice. Next we present the methodological and conceptual framework for the field study, including the research methods used, architecture firms studied and empirical material collected. The result sections first focus on when and what architects (want to) know about user experience, highlighting the contingency of information handling and unpacking the notion of 'user experience'.

Subsequently, we trace out two particular routes of how architects acquire embodied knowledge, as observed in the fieldwork. These examples help us unravelling the socio-material environment in which knowledge about user experience is mediated. Finally, we reflect on how the nature and particular mechanisms of architects' knowing about users, as observed, set preconditions for supporting them in addressing user experience.

\footnotetext{
${ }^{1}$ We are aware of the body of knowledge on the role of intuition in design decision-making (e.g., Badke-Schaub \& Eris, 2014), however, diving into the topic of tacit knowledge in design exceeds the scope of this study.
} 


\section{Background: Informing design practice}

Informing design practice requires acknowledging the (differences between) knowledge cultures in research versus design practice (Diaz Moore \& Geboy, 2010; Niedderer, 2007). The distinct nature of the design discipline is described by Archer (1979) as 'designerly'. Cross (1982) articulated 'designerly ways of knowing', embodied in design processes as well as products. Derived concepts like 'designerly tools' advance an understanding of the nature of design practice as indispensable for, e.g., developing new approaches or tools to successfully support it (Stolterman, 2008).

Informing architects about user experience - entailing people's personal experience and often implicit knowledge - is not straightforward. It requires a particular understanding from designers to adopt the information and put it to practice (Kirkeby, 2009) in the reflective process of assessing potential solutions (Schön, 1983). Extensive information supply suits the rational and deductive process of a problem-oriented approach, but is not compatible with designers' solution-oriented way of working. The latter is characterised as exploratory, since a design proposal looks for something new that transcends the obvious; emergent, since relevant features emerge in putative solutions; opportunistic, since the process is influenced by what is learned along the way; rhetorical, since it aims at developing a compelling argument; and risky, since it involves making a personal commitment (Cross, 1999). It is clear that this particular way of working sets specific requirements for information to be relevant to design practice.

Recent studies aimed at promoting knowledge transfer in different contexts (e.g., care, education) have analysed architects' information requirements regarding users (Van der Linden, Dong, \& Heylighen, 2016b; Annemans, Van Audenhove, Vermolen, \& Heylighen, 2014; Kirkeby, Jensen, Larsen, \& Kural, 2015; McIntyre \& Harrison, 2016). Rather than prescriptive rules or extensive reports, architects prefer open-ended information on experience-related aspects relevant to the design; they particularly appreciated information that is hands-on, visual, rich, structured and reliable; they valued insight into underlying questions, contextual guidance and relation to clients' motivations as these support decision-making; they appreciated face-to-face communication; and recognised the need for additional sources and tools to engage with users.

Studies based on architects' self-reporting provide only limited insight into the application of this knowledge base (Kirkeby et al., 2015). Architects may not be fully aware of the knowledge they are drawing on, because of habits and preconceptions about 'knowledge'. Moreover, focusing on (the characteristics of) sources grants little insight into what happens with this knowledge during the 
design. Further research into this area needs to broaden the perspective and observe what happens during the course of design projects, in real-world design contexts.

Some studies about architectural practice have pointed at the complexities of knowing (about users). Concepts like 'aesthetic knowledge' (Ewenstein \& Whyte, 2007) and 'professional vision' (Styhre, 2011) have been developed to account for these characteristic, tacit aspects of architects' knowing. Complexities may relate to the environment of design practice, where knowledge is mediated by, for instance, practice culture (Schmidt \& Dainty, 2015), interdisciplinary collaborations (Kasalı \& Nersessian, 2015) and the materials used herein (e.g., Luck, 2007; Murphy, 2005). Diving into this interactive network of social and material actors (Yaneva, 2009) may provide clues about these particular ways of knowing about users that complement understandings based on studying (individual) designers' cognition.

\section{Field study}

\subsection{Research approach}

Starting from an understanding of design as situated in and distributed across a socio-material environment (see Bucciarelli, 1994, in engineering design; or Le Dantec, 2010, in architectural design), we adopted an ethnographic research approach, situated in this environment. This methodological position inscribes the study in the practice turn, pioneered by Cuff (1992) and more recently gaining support in research into professional cultures like those involved with architectural design (e.g., Demian \& Fruchter, 2006; Ewenstein \& Whyte, 2007; Kasalı \& Nersessian, 2015; Oygür, 2018; Yaneva, 2009, 2018). Through this approach, we aim to include the commonplace, embedded and encultured (so often implicit) side of design practice.

Against the background of daily design practice, architects' knowing about users is investigated as the topic of this study. In order to promote knowledge transfer on user experience, we consider a holistic understanding of this practice essential to gain insight into the principles and practices of knowing about users. In the context of science and technology studies, this line of reasoning relates to 'ecological thinking':

An ecological approach [...] emphasizes that multiple and varying elements contribute to the success of an idea or artefact - and any element in an idea or artefact's environment may be responsible for failure. (Sismondo, 2004, pp. 69-70) 


\subsection{Participating architecture firms}

Insights were gained through an ethnographic study in three diverse, renowned architecture firms in Belgium. Table 1 introduces the participating architecture firms, including details on their organisation, portfolio, professional values, and workspace. For reasons of confidentiality, firm names have been replaced by pseudonyms. The firms and projects were selected to cover a broad range of project types and procedures. Also convenience played a role in the selection, in terms of the firms' openness to participate in research and the ongoing projects at the time of the study. As such, architects' ways of knowing about user experience could be triangulated across different types of firm and project settings. 


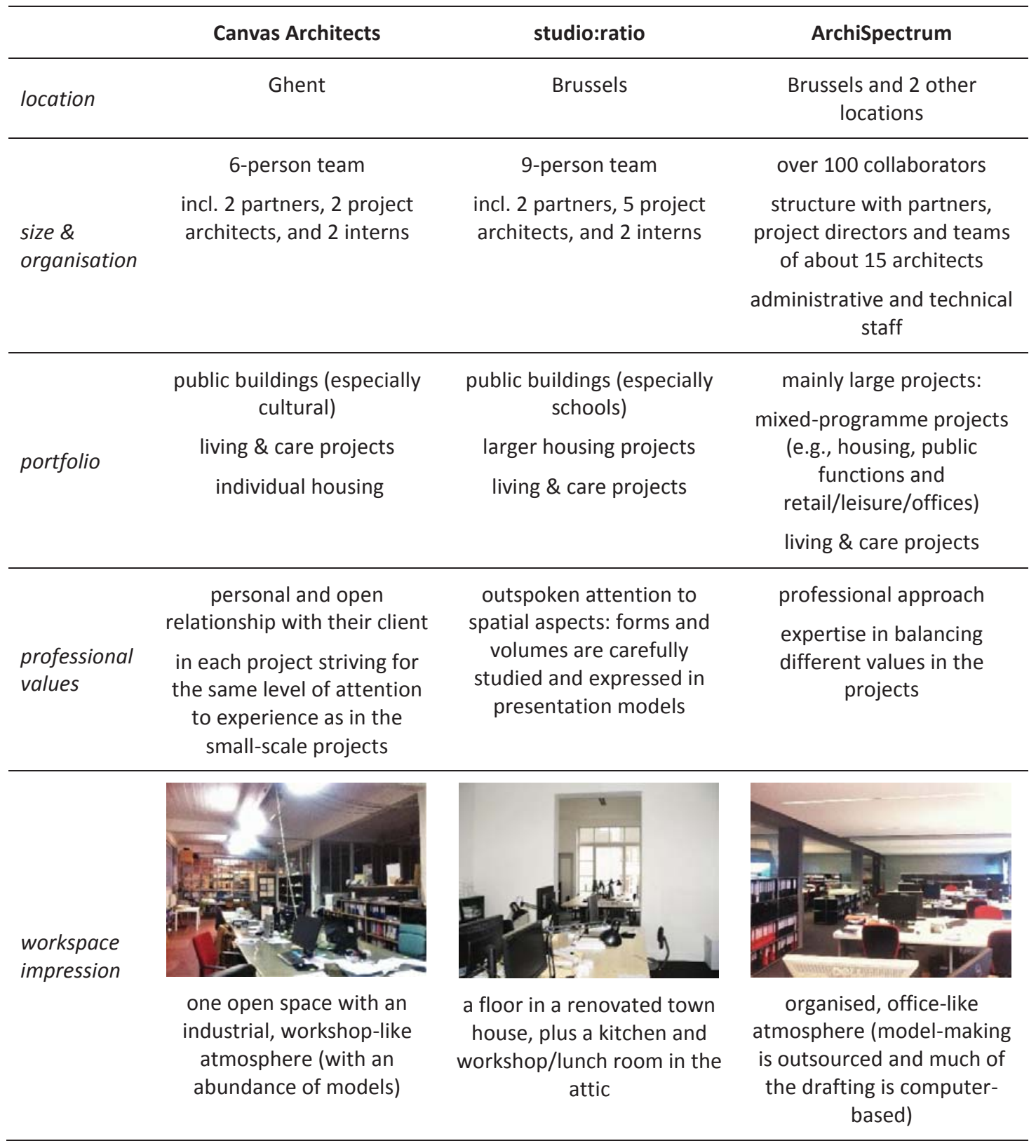

Table 1. Introduction to the participating architecture firms.

\subsection{Data collection}

The first author visited each firm during a six-week period. She was assigned a desk in the architects' office space, and granted access to design meetings and documentation. In consultation with the partners, she followed four to five of the projects the architects were working on at the time. Rather than deciding upfront about a particular focal practice (e.g., sketching) to investigate on a micro scale, she tried to remain open to the full complexity of the socio-material environment and adapt flexibly in response to the realities encountered in the field setting. 
Data were collected through observations (almost 400 hours), in-depth interviews (most with architects, some with partnering firms or clients) ${ }^{2}$ and document analysis (including briefing documents, meeting reports, drawings, models, ...). This mix of ethnographic techniques balanced what architects say (through insiders' self-report) with how they act (through outsider's observation) and allowed meaning to be co-constructed in dialogue with participants. Table 2 displays details about the collected data. Interviews were audiotaped and transcribed, while observations were documented in field notes (including daily journal-like entries about ongoing activities and conversations, first impressions and interpretations, and detailed note-taking during meetings). For a more elaborate description of the research methods and their relation to the findings, we refer to a paper based on the study in the first firm (Van der Linden, Dong, \& Heylighen, 2016a).

\begin{tabular}{|c|c|c|}
\hline $\begin{array}{l}\text { Canvas Architects } \\
\text { fall } 2015\end{array}$ & $\begin{array}{l}\text { studio:ratio } \\
\text { fall } 2014\end{array}$ & $\begin{array}{l}\text { ArchiSpectrum } \\
\text { spring } 2016\end{array}$ \\
\hline$\underline{128 h s \text { of observation }}$ & $\underline{129 h s ~ o f ~ o b s e r v a t i o n ~}$ & $\underline{139 h s ~ o f ~ o b s e r v a t i o n ~}$ \\
\hline 2 internal meetings & 6 internal meetings & 5 internal meetings \\
\hline 5 external meetings & 1 external meeting & 3 external meetings \\
\hline $\begin{array}{l}\text { extensive indirect observations \& } \\
\text { informal interaction }\end{array}$ & $\begin{array}{l}\text { extensive indirect observations \& } \\
\text { informal interaction }\end{array}$ & $\begin{array}{l}\text { extensive indirect observations \& } \\
\text { informal interaction }\end{array}$ \\
\hline$\underline{6 \text { in-depth interviews }}$ & $\underline{5 \text { in-depth interviews }}$ & $\underline{5 \text { in-depth interviews }}$ \\
\hline 2 partners & 2 partners & CEO \& project director \\
\hline 1 architect & 3 architects & head of interior architecture \\
\hline 2 persons from associated firms & & 1 team leader \\
\hline \multirow[t]{2}{*}{1 client } & & 1 architect \\
\hline & & 1 client \\
\hline 4 projects followed & $\underline{5 \text { projects followed }}$ & $\underline{5 \text { projects followed }}$ \\
\hline $\begin{array}{l}\text { cultural facility } \\
\text { housing for people with a mental } \\
\text { impairment }\end{array}$ & $\begin{array}{c}\text { housing for older people } \\
\text { town hall } \\
\text { social housing }\end{array}$ & $\begin{array}{c}\text { mixed project (town hall, retail \& } \\
\text { housing) } \\
\text { leisure facility }\end{array}$ \\
\hline $\begin{array}{l}\text { housing for people with } \\
\text { dementia }\end{array}$ & $\begin{array}{l}\text { residential care facility for people } \\
\text { with dementia }\end{array}$ & $\begin{array}{c}\text { mixed project (schools, leisure \& } \\
\text { housing) }\end{array}$ \\
\hline $\begin{array}{l}\text { single-family house with office } \\
\text { space }\end{array}$ & intergenerational housing & $\begin{array}{l}\text { housing with care facilities } \\
\text { social housing }\end{array}$ \\
\hline
\end{tabular}

Table 2. Overview of the data collected in the field study.

\footnotetext{
${ }^{2}$ One interview (at ArchiSpectrum) was conducted in the context of an earlier exploratory study (see Van der Linden, Dong, \& Heylighen, 2016b). Because of its relevance and complementarity, it was included in the data set.
} 


\subsection{Analysis}

Our empirical study seeks to articulate architects' knowing about users, tracing user experience as attended to and embedded in design practice (e.g., how knowledge about users - referring to their 'experience' - was generated, shared, transformed and represented). The empirical material was analysed in a qualitative way, through coding and the development of memos, based on a combination of concepts from literature and aspects that surfaced from the empirical material.

In literature, no consensus seems to exist on how 'user experience' is conceptualised. Typically, experience in/of architecture is associated with the sensory perception of space (e.g., Holl, Pallasmaa, \& Pérez-Gómez, 2006). Acknowledging the complexity of elements that contribute to people's spatial experience, Medway (2000) identifies functional/structural, perceptual, phenomenological and symbolic elements of architectural design, proving useful in discourse and conversational analysis (Luck \& McDonnell, 2006; McDonnell \& Lloyd, 2014). In related design disciplines, several subdivisions have been suggested to describe human-product experiences (see Vaes, 2014, p. 28 for an overview), including Krippendorff's (2006) distinction between sensing / acting / meaning, Norman's (2004) visceral, behavioural and reflective levels, or Desmet's (2002) non-instrumental, instrumental and non-physical interaction components. In analysing our empirical material, we used these subdivisions as sensitizing concepts, to relate different ways in which architects know about user experience to different facets of user experience (see section 4 below).

We approached and compared the empirical material repeatedly different angles, confronting different types of data, participant perspectives, and projects. Because of the different contexts, the study in each firm offered insights into particular aspects: whereas the study in the first firm focused on sources of information about users and its further application in design, the smallest firm provided additional insights into collaborations, and the largest one into knowledge sharing initiatives and complexities. Initial analyses for each firm were combined and further elaborated afterwards. Initial overall findings were checked with participants in follow-up interviews in each firm. The findings are illustrated with quotes from the interviews, transcribed verbatim and translated by the authors, and with (adapted) field notes.

\section{Contingency of when information is handled}

The ethnographic study shows that architects absorb knowledge about user experience from a plethora of sources. The observation that knowledge is often not made explicit and seldom documented makes it challenging to trace back its sources. In the interviews, architects were better 
in pinpointing the information that was deliberately collected in a certain project (e.g., consulting a document) than in explaining the more intuitive ways of knowing. They did acknowledge that there was more knowledge involved: using terms like "intuition" and "(professional) experience", they referred to an implicit body of knowledge characteristic of the architectural profession. Moreover, architects reported many coincidental findings and random as opposed to targeted searches. Many things happened "in the margin", i.e., not in the context of a specific project, yet nourished their inspiration or knowledge base. Sources that seemed peripheral to a particular project might actually form a connecting thread in the firm's repertoire, informing parallel or future projects.

The contingency of information handling became particularly clear in an interview with a partner (P1) at studio:ratio, who was asked to map an overview of the sources the architects drew on in designing school buildings, in relation to the different design phases. As illustrated by the resulting map (Figure 1) and interview extract, the partner had to revise his categorisation according to the different design phases and add a column "in the margin" for sources (e.g., books, symposia, visits) that were not exclusively tied to or synchronised with the project. 


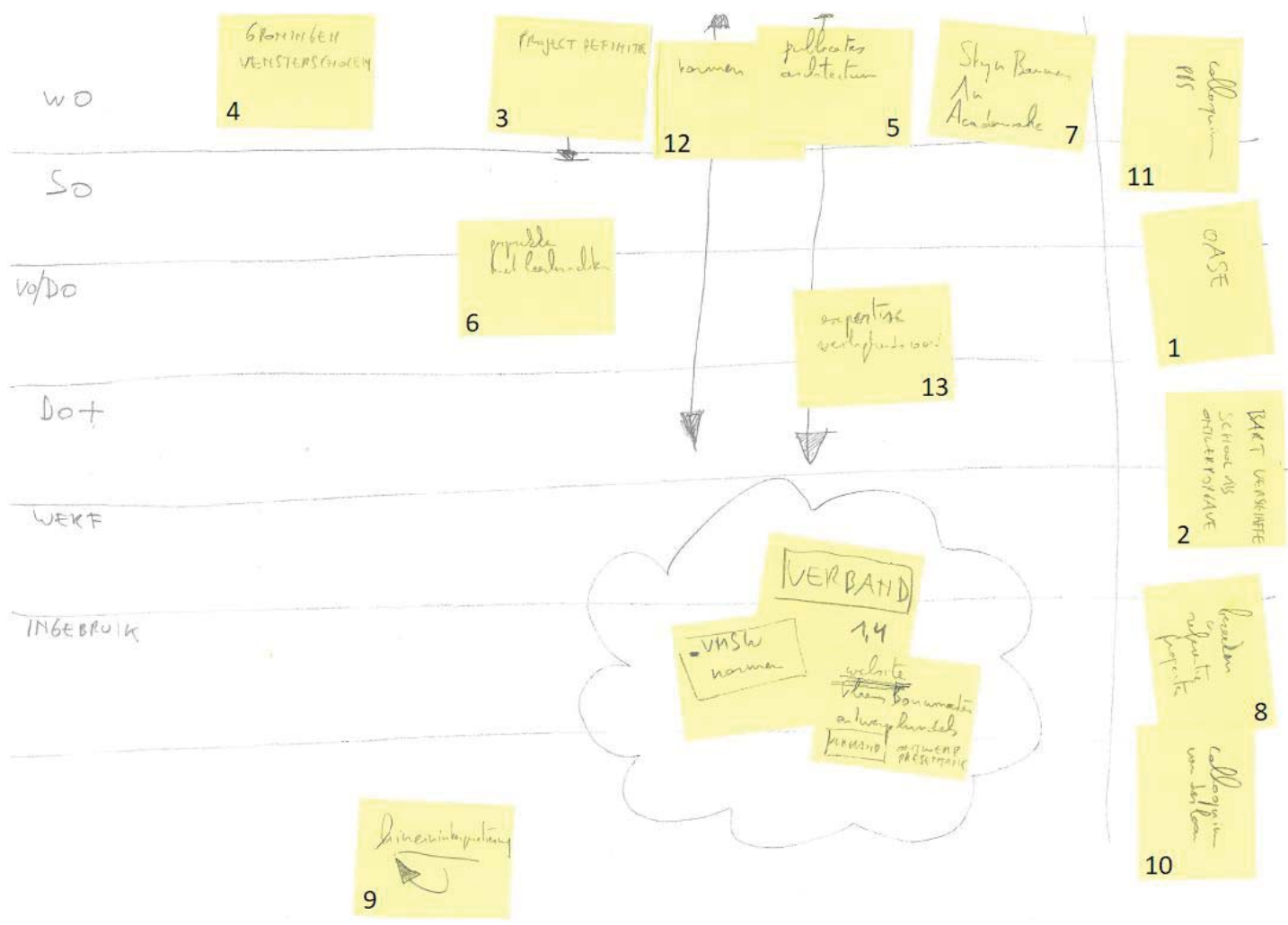

1. OASE [an architectural journal]

2. Bart Verschaffel - 'School als ontwerpopgave' [an architectural book about school design]

3. Project definition

4. Groningen Vensterscholen [community schools in the Netherlands]

5. Publications architecture

6. Conversations with teachers

7. Stijn Baumers, Ann, academic [researchers with a project on architecture and autism]

8. Visits to reference projects

9. Hineininterpretierung [(re)interpretation of the design/concept later on]

10. Seminar van der Laan [seminar about a reference architect]

11. Seminar public-private partnerships

12. Standards

13. Expertise safety coordinator

Figure 1. Map of the different sources drawn on in designing school buildings, in relation to the different design phases (listed horizontally), drawn up by a partner of studio:ratio. The entries are numbered according to their appearance in the interview and translated. The post-its in the cloud were jotted down to illustrate a point about missing information and do not follow the classification. 
05:50 P1 (...) What kind of stayed with us as an ideology is that- and then maybe I should refer to an article in OASE from a few years ago about school design. It was an article about- I don't know whether I've mentioned that already?

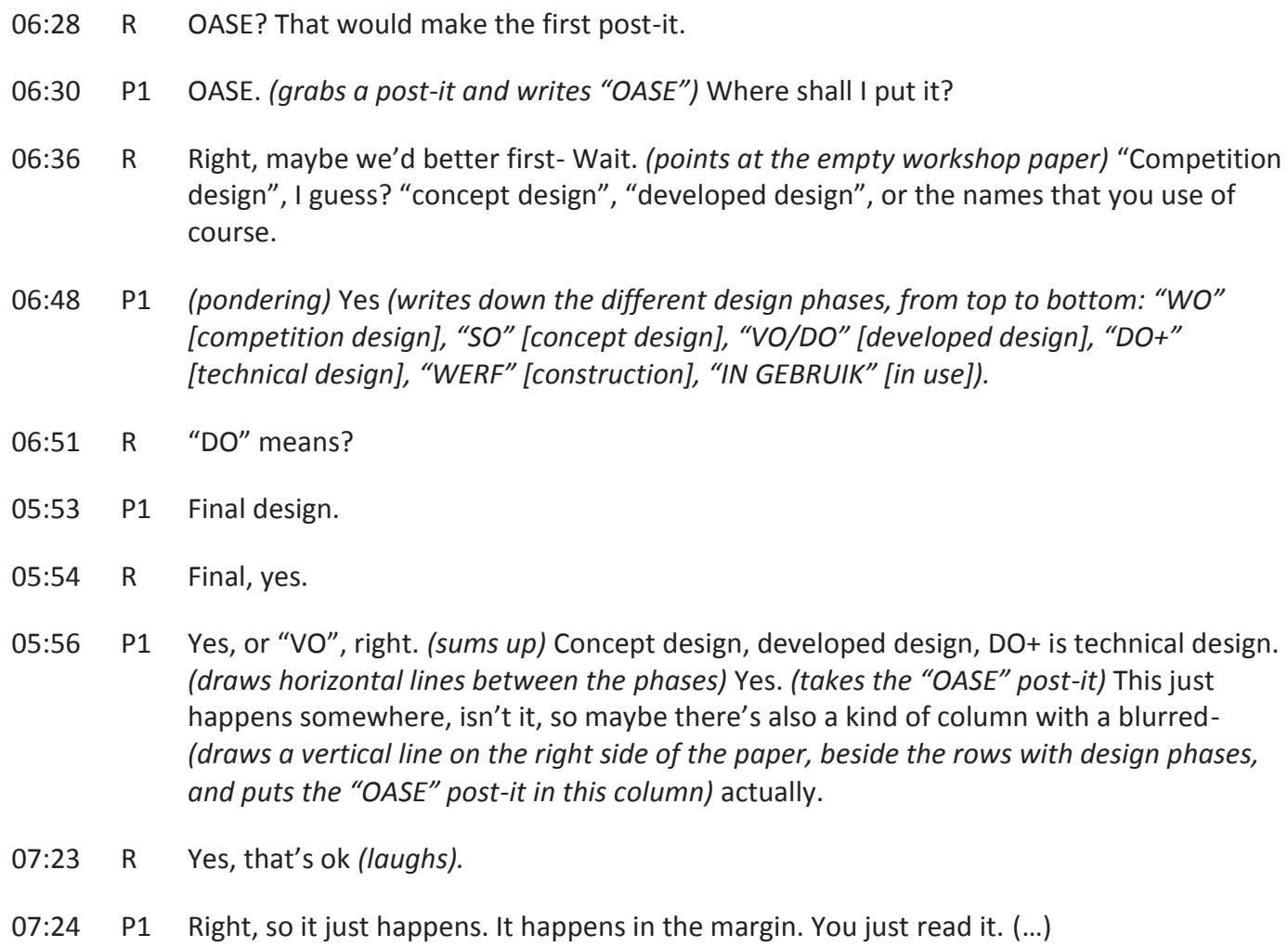

This informal and opportunistic way of working with information seems to be a pragmatic strategy to deal with the limited time resources and incomplete problem definitions that characterise design practice. As a result, some architects might not even experience a need for information about user experience - unless the use context is remarkably unfamiliar - and just work their way through the project based on implicit assumptions. The potential pitfall of the ingrainedness of assumptions was reflected on by an architect at studio:ratio:

I think the most dangerous thing as an architect- well, what many architects do and what is inevitable, I think, is that you often start from assumptions, right. You assume a lot. And you think "that's a good idea", but sometimes, well, in reality it doesn't work.

\section{Facets of what user experience entails}

As the mapping exercise in the previous section shows, sources about user experience can range from the conceptual to the very practical. Our study also identified a variety in needs for and ways of working with information, which could be related to different facets of user experience. To unravel 
the complexity of architects' (unarticulated) knowledge questions regarding user experience, a subdivision of the facets of experience, as referenced in section 2.4, provides a helpful lens. Based on our empirical material, we distinguish between questions of how a space feels, how it works, and what it means, as outlined in Table 3 and illustrated in the subsections below. Note that these facets can interrelate, as, e.g., meaning is associated with spatial organisation and materials.

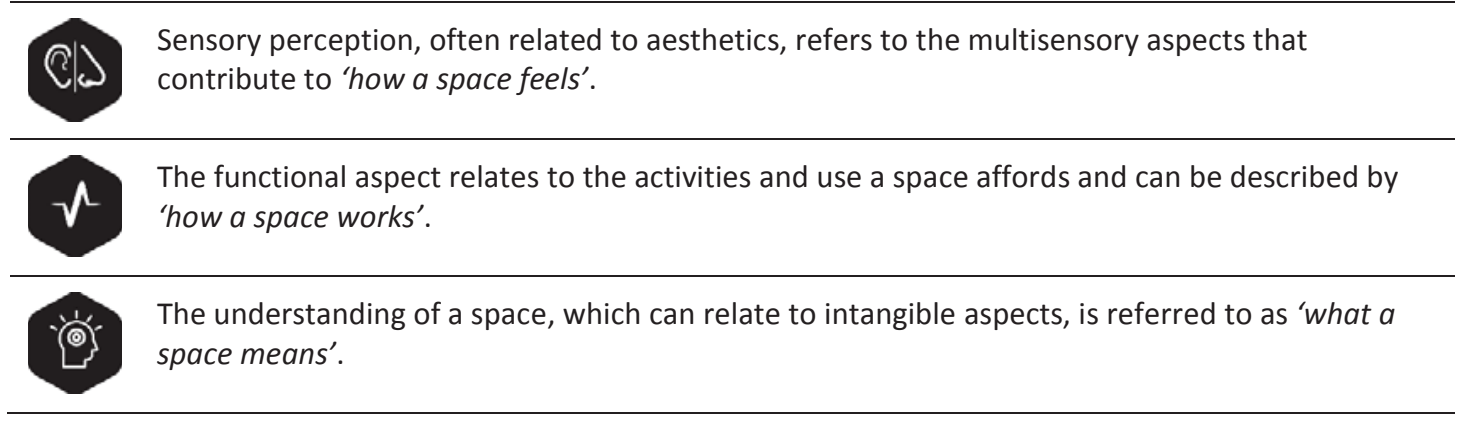

Table 3. Facets of user experience in architecture.

\subsection{How a space feels}

'How a space feels' seemed to be considered at the core of architects' expertise. In designing a new building, architects would draw on their previous design experience and would analyse other buildings in terms of how materials (with their colours and textures) and proportions give rise to a certain expression. This involved questions like how to link up spaces, assemble elements into a rhythm, or define the borders of a space. The materialisation of the design at hand was subsequently analysed in sketch models, elevation drawings or 3D simulations, which were often put before or attracting the attention of colleagues and became the topic of debate. In meetings with clients, we observed the architects' taking an expert position in this area, as they would typically propose certain materials and try to convince or obtain approval from their client. Concerning this facet of experience, little information was sought explicitly, as architects mainly drew from the implicit body of knowledge in their profession. 
Box 1: example of architects addressing how a space feels
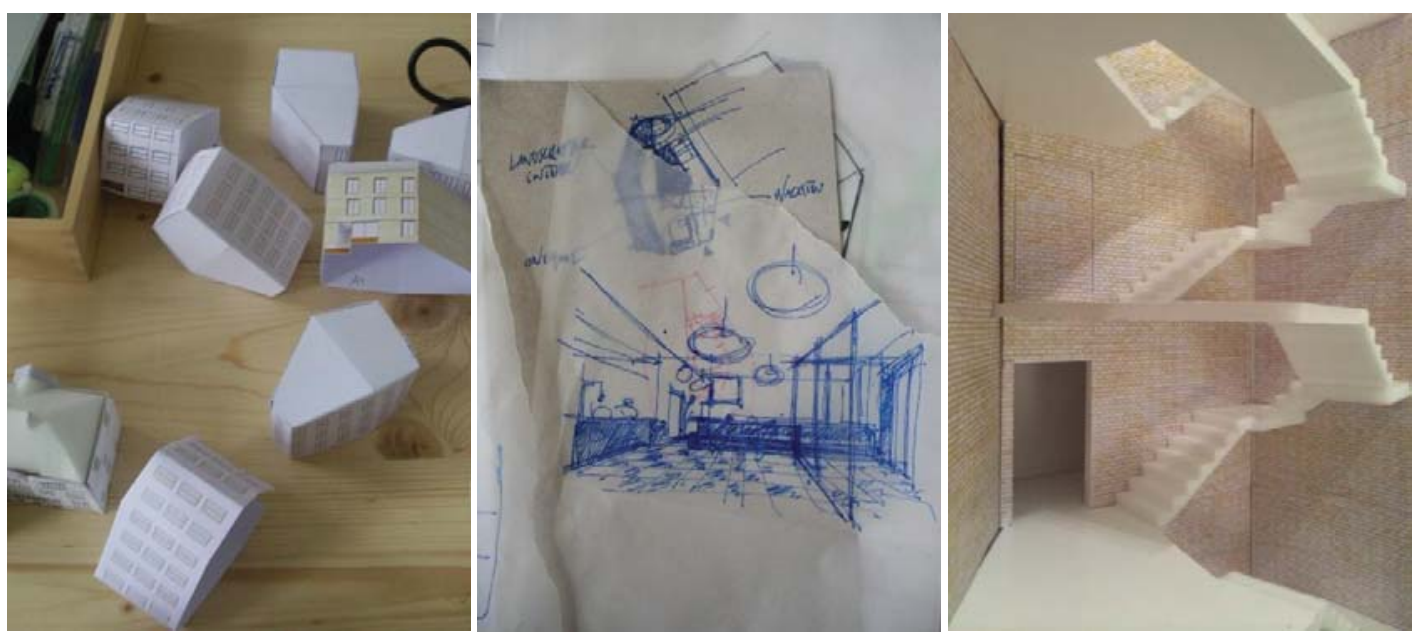

During the redesign of a town hall, the architect working on this project followed at studio:ratio repeatedly tested configurations of windows in and materialisations of the façade in small paper models (left picture), or sketched spaces like the entrance area to understand the atmosphere (middle picture). This kind of studies were made individually as part of the design process and communicated with the partner only. Crucial elements of the design, on the other hand, were carefully visualised in a detailed presentation model, such as the staircase (right picture), which was made by colleagues, to convince the client during a meeting.

\subsection{How a space works}

'How a space works' is a completely different matter, being the facet that was questioned most frequently in the architecture firms. During architects' design process, the relation between activities and spaces recurred as a key issue. It was an important thread when architects were analysing reference projects (usually through floor plans and schemes) as well as the building programme of the project at hand (translated into an organigram). Many of architects' explicit information requests (i.e., active searches for and discussions of information) highlighted a need for insight into daily activities in a building. This includes questions like where do people go, how is lunch organised, how do people want to work. This type of information ranged from concrete requirements to the motivation behind them and ultimately informed architects' assessment of certain design decisions in terms of their impact on user experience. Obtaining this knowledge, especially in unfamiliar contexts, and organising spaces in order to accommodate user needs, requires sources close to people's everyday life. 
Box 2: example of architects addressing how a space works

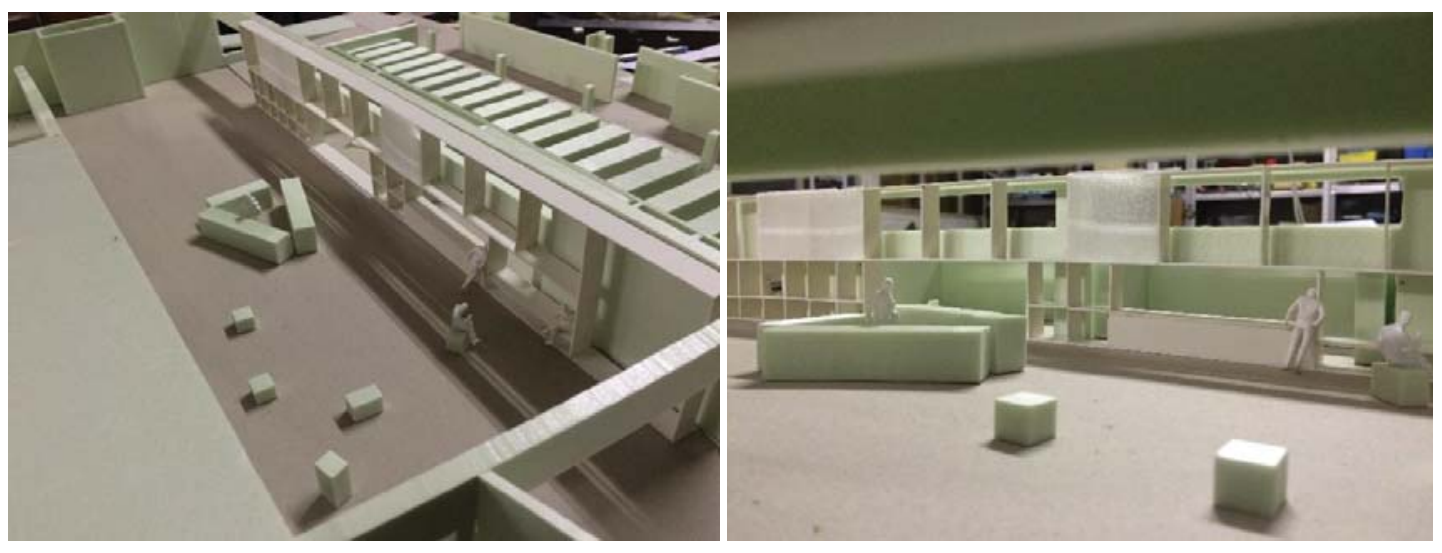

During a group session observed at Canvas Architects, the architects brainstormed about the entrance area of a cultural building they were redesigning. They acted out scenarios by moving around furniture elements in foam, but were unsure about how crowds would behave at the start and end of performances and about how a reception desk was to function in this chaos. After referring to many other buildings they had visited, the architects joked that they should be offered free tickets to check out the situation on site, suggested the idea of installing a mock-up (which was not realised), and concluded that they needed information from the staff working there to take the design a step further.

\subsection{What a space means}

'What a space means' was less frequently addressed as a topic in itself, but sometimes appeared in relation to how a space feels or works. Architects often had personal ambitions regarding, e.g., housing quality, in line with their - mainly implicit - professional values. Information about the meaning of space became more explicit through occasional narratives of the client (e.g., the client's philosophy or personal stories), which architects easily picked up and incorporated in the design rationale. During competition stages, in contrast, architects often reported a lack of information about the priorities of the (un-consultable) client. 

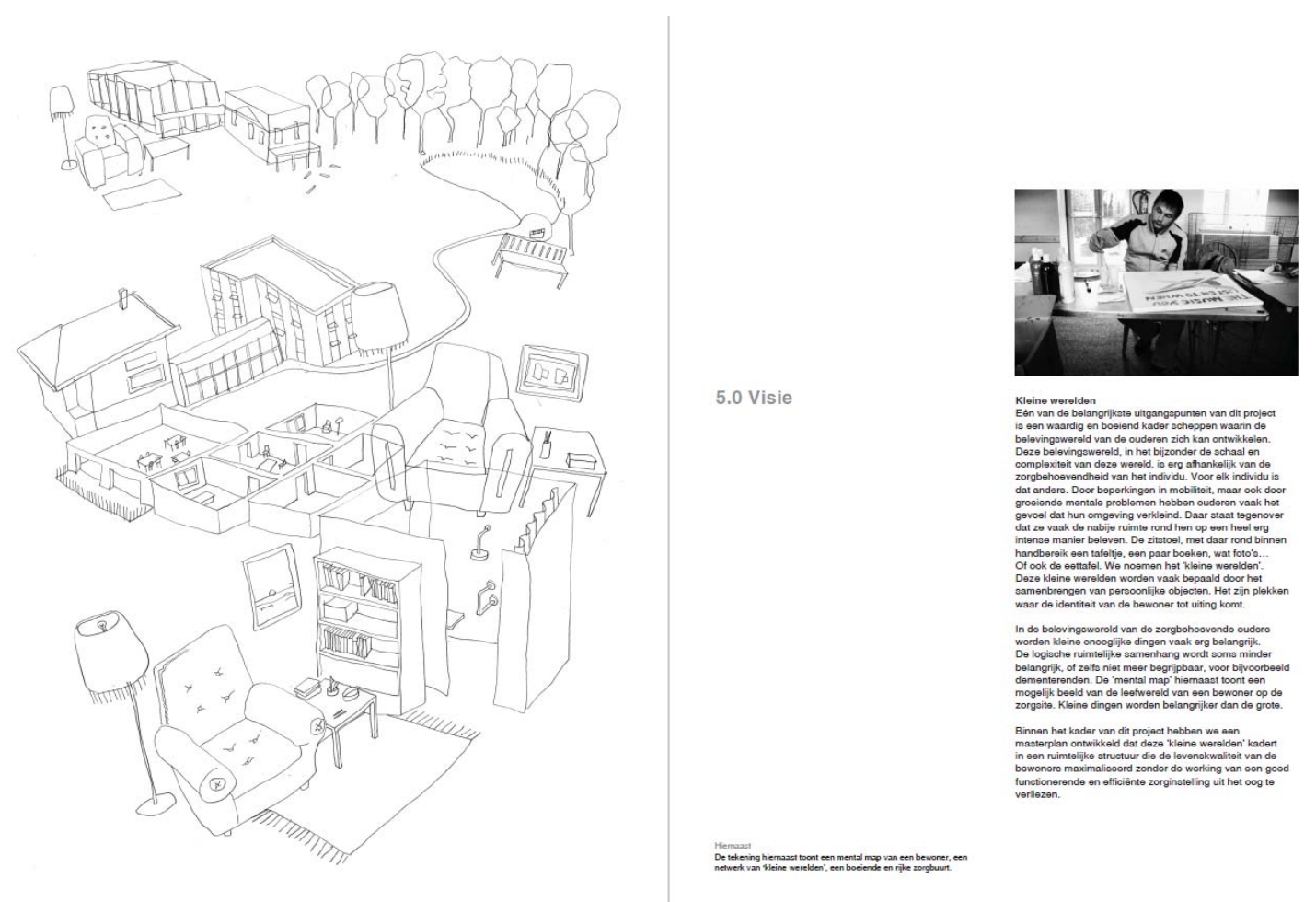

For the competition design of a residential care facility for people with dementia, the architects at studio:ratio developed the concept of a network of "little worlds", which refers to a person with dementia's fragmented experience of home. They explained that they encountered the "little worlds" in an ethnographic research publication and coupled it to the organisational concept of a campus, which they were working on in response to the Flemish Government Architect's call to address the tension between the small and big scale in care architecture. The picture shows their vision note and drawing (a resident's mental map) in their competition entry. This user-experience-based concept proved successful for guiding design decisions that aim for hominess at different design scales and for representing the project (see Van der Linden, Van Steenwinkel, Dong, \& Heylighen, 2016).

\section{$5 \quad$ Routes to how embodied knowledge about users is acquired}

Although information about user experience was usually handled sporadically and information requests were often implicit, we did observe a few situations in which knowledge about user experience was acquired actively (as opposed to drawing on personal experience or factual information in design briefs). By way of example, we discuss two of these routes encountered in the field study: 'visiting reference projects' as a common strategy used in different project types, and 'infiltrating in users' life' as an exceptional and the most intensive strategy to get closer to users' perspectives. 


\subsection{Route 1: Visiting reference projects}

Based on our study, visiting reference projects seems to be a common strategy to find out about user experience and is applied among different project types. The following quote by a partner at Canvas Architects compares the insights produced by a real-life visit versus studying visual material only:

So it's a three-dimensional experience. You talk to the operators, actually, you talk to the one who runs [the facility]. You see how particular patients move in there. You see how doors are sometimes out of place. In a picture a door can look very nice, but then the director is standing next to you and says "that's my biggest mistake here, sliding doors", whereas in that picture you can't see how totally misplaced that sliding door is.

Visiting reference projects could involve talking to the facility's principal or someone who was involved in its design and/or construction (e.g., technical director), but usually not to the people working and living there. The architects interviewed regularly undertook holiday/study trips to favourite architects' buildings. Since their excursions were rather individual and only documented in pictures, the insights gained were difficult to share. A particular project could also be an occasion to visit reference projects. For example, studio:ratio visited such projects in the context of their design of a residential care facility and were very enthusiastic about this (rather exceptional) group initiative. It yielded a shared understanding of the context, an ap/depreciation of buildings and a repertoire of design strategies. An architect at studio:ratio explained the practical relevance of such visits as follows:

On the one hand it was [a matter of] realising "how does such a living unit work?" and, for example, the importance of a central kitchen in a living unit, or what that place means and what the living room means. And also the importance of freedom in circulations [...] there's a sort of dual opportunity to circulate [...] and that creates a kind of luxury, a sort of freedom, within this communal living in one apartment with people you don't know or haven't chosen yourself. [...] And on the other hand, [...] that was very interesting as well to [understand] how the architecture, or just the building itself, how this relates to its inhabitants, and how it breathes a kind of atmosphere, and how small gestures can bring about a kind of scenes or benchmarks.

This example illustrates how, in the architects' insights into the reference project, the different facets of experience are intertwined. The fact that this intertwining is preserved, makes the knowledge more easily applicable in design (as opposed to working on materialisation and 
separately applying decontextualized facts on the facility's operation in the plan). It also shows how much the assessment is based on architects' own experience and interpretation of the building. Another architect at studio:ratio remarked that architects are specifically skilled to trace architectural quality, highlighting their expert position when it comes to sensory perception: "The difference with a... normal, between brackets, human being, is that you [as an architect] can trace this: 'how come that this feels good?'."

\subsection{Route 2: Infiltrating in users' life}

In general, the architects indicated a need for immersion in users' daily environments in case of highly unfamiliar users (e.g., people with impairments) or contexts (e.g., juvenile detention) and less so in the case of "the general public" or "places we all know" like offices and schools.

Direct contact with users (i.e., consultation) was exceptional according to the participating architects. However, in the context of renovating and extending a house for people with dementia, Canvas Architects was convinced about joining in with users. This was observed as the most intensive strategy to find out more about users' context and needs. One partner and architect stayed over at the client's current house for people with dementia for 24 hours, which made a deep impression and was experienced as a game-changer.

During lunch break, the architect who stayed over at the house for people with dementia mentioned that he learned so much during this visit, more than he was able to write down. When the new intern asked about how this featured in the design, the architect replied that it is actually hard to see a direct impact on the design, but that it is rather about small things, such as designing the windows not overly large but a bit more sheltered as not to expose people. (field notes)

During their respective in-depth interviews, both this architect and the partner who did not join the stay-over (but took over the project from his colleague) reflected that those who had infiltrated had a very different understanding than those who had not. The knowledge the former had acquired surfaced in practical discussions about the design and acted as an authority argument, countering the assumptions of the latter. The complexity of their experience was preserved (in these "small things"), but was not easily expressed.

This example suggests that direct contact with users is not necessarily the most evident way to bridge use and design contexts. Since the knowledge about user experience was embodied only in the persons who had stayed over, deploying it in a team project was not self-evident. 


\section{The socio-material environment in which knowledge is mediated}

As the previous sections showed, the sources that constitute architects' knowledge base are not well-delineated but fluid in nature. Often it is a particular combination of people and materials that enables knowledge transfer. This section outlines, on a more general level, how the socio-material environment of design, a dynamic composition of the people and materials involved in knowledge transfer, mediates knowledge about user experience in design practice. Untangling this composition is helpful for clarifying the challenges for transferring knowledge about user experience.

The study made apparent two significant streams of knowledge in architects' daily design practice. On the one hand, much knowledge seemed to reside in the architectural profession itself. The architects in the study heavily relied on personal experience, as well as on knowledge embedded in the constellation of their teams, firms, associations and community. On the other hand, additional and not the least important - information was gathered in the context of specific projects, mainly through the client. This project-specific knowledge eventually became incorporated in architects' knowledge and could in turn inform other projects. Below we untangle first the social aspects of both architects' and clients' spheres, and next the material aspects.

\subsection{Social mediators in the architect's sphere}

'The architect' should be interpreted not as a single person, but rather as a social constellation, especially in more complex projects, such as those that are subject to our study. The core of this constellation can be considered an individual, yet multiple social layers shape and provide the knowledge this individual can tap into. In our understanding of 'the architect', we distinguish four different layers, ranging from individual to collective.

At the micro level, individuals bring their own experience, values, tools and skills, personal acquaintances, experience from previous firms and so forth. We encountered, for example, individuals who were inspired by buildings they visited on a trip (incorporating elements contributing to how space feels), had particular ideas about living standards and architectural quality (infiltrating in how their designed spaces work), or were driven by the situation of, say, a grandparent (inserting meaning in design decision-making). In the town hall project (box 1), for example, architects were set to work according to their (representation) skills, whereas in the cultural building project (box 2), they were brought together to increase the personal experience to tap into.

One level up, each firm has specific professional values and ambitions, builds up a knowledge base and maybe even expertise through its projects. Yet, since firms distribute knowledge and tasks in a 
project among their staff, knowledge transfer within the firm is often not self-evident (as illustrated by Canvas Architects' stay-over, see section 5.2). Someone's position within a project raises a particular perspective on that project, as roles and responsibilities (e.g., conceptualising vs. detailing) come with particular information needs and sources. In general, knowledge about user experience in design practice stays very much person-bound, with knowledge transfer basically coming down to addressing the right person. As the head of interior architect at ArchiSpectrum remarked:

Knowledge simply resides within people. That's just part of the nature of an architecture firm. If... tomorrow half of the staff is replaced by new people, then I think we'll be going through a serious slump... in terms of quality, expertise, the way of interacting with each other... Yeah. So we try to share that knowledge.

Another level up, architecture firms can choose to associate themselves with other firms that bring additional expertise - in architecture or related domains (e.g., sustainability, building physics, stability, project management) - or to outsource aspects like rendering or model making to specialised firms. This can happen in the context of a specific project or result in a long-term collaboration (e.g., Canvas Architects was often asked as a consortium partner to cover user experience). In these associations as well, knowledge is distributed among collaborators that have their own tools for reflective practice and bring their own values to the project.

At a macro level, there is the architectural community, which sets the tone of the professional discourse. We observed importance being attributed to themes outlined by the Flemish Government Architect (e.g., 'invisible care', as in the case of the residential care project (box 3)) or by professional associations organising trainings, events and symposia (e.g., on accessibility, school buildings, ...), as well as to leading schools (e.g., ETH Zürich) or fellow architecture firms (e.g., in terms of architectural materialisation or representing atmospheres). The culture of peer-recognition amplifies ambitions and perceived responsibilities in architects.

Hence, attention to user experience is mediated at different levels of architects' social constellation. This means that an architect can find relevant input and stimuli to address user experience in their personal sphere and their firm, or even with the collaborators and the broader architectural community. However, the distributed nature of this knowledge and decision-making, in general, presents challenges to knowledge transfer. This may hamper the implementation of one's intentions regarding user experience, or result in the elimination of particular design features in later stage if others in charge at that point do not fully grasp the underlying motivations. 
The socially layered constellation (Figure 2) can be considered a background of an individual architect (e.g., his/her professional baggage) but also a foreground (e.g., when a colleague has a more direct relationship with the client). Note that the constellation is dynamic. On a project level, more or less other individuals can take or change positions (e.g., in between an individual architect and client), depending on the project type and stage. On a higher level the constellation is dynamic because the values and themes that are topical in the architectural community fluctuate constantly.

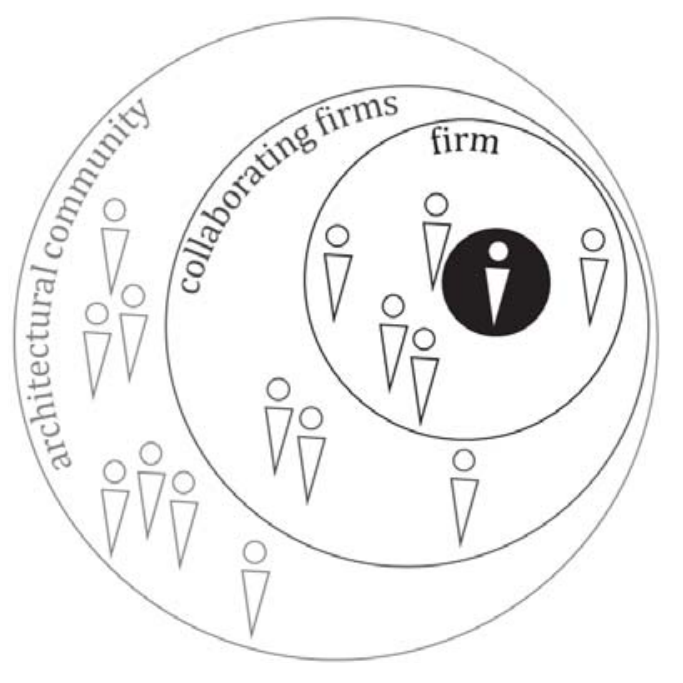

Figure 2. Social layers of the architects' sphere.

\subsection{Social mediators in the client's sphere}

In the context of a particular project, the architects' sphere is permeated by the client's. The project's framing by the client highly influenced architects' take-on. A partner at studio:ratio, for example, pointed out that the diversity among their school projects reflected the diversity in clients' questions - ranging from technicalities like spatial efficiency to social themes like citizenship.

Just like 'the architect', 'the client' is rarely a singular entity, but most often a social constellation. If we consider the decision-making actor at the core of this constellation, this (group of) person(s) is not necessarily the one interacting with the architect, and even less probably the building's enduser. Between this decision-maker and the architect can be a (team of) representative(s) in charge of the regular contact with the architect. At the other end of the constellation, there can be the clients' staff and/or customers who will use the buildings on a daily basis. How clients know about their endusers is a knowledge issue as such, in relation to which we observed a multitude of strategies (e.g., working groups, resident consultation). The notion of 'the client' becomes even more complicated when commissioning and financing parties do not coincide (a frequent situation at ArchiSpectrum). From an individual architect's perspective, juggling with different social actors' expectations can feel 
like being caught "between four fires" (i.e., architecture firm head, client representative, financer/developer, local authorities). Moreover, given all these different parties involved - with or without a voice in (particular stages of) the project - making decisions for the benefits of 'the user' can be hard.

Regardless of their composition, clients are highly diverse, which affects the relationship with architects. Firstly, not all clients have experience in commissioning a building and can encounter difficulties, e.g., in drafting a project brief. Secondly, clients differ in their attention to user experience. Finally, they can also differ in availability, with the opportunities for knowledge exchange being heavily dictated by the project procedure. These factors affect architect-client dynamics, which play a decisive role in how user experience is addressed (see Van der Linden, Dong, \& Heylighen, 2017).

\subsection{Material mediators}

Knowledge about user experience is mediated by a variety of 'objects', from the general and generic (e.g., norms) to the concrete and contextual (e.g., buildings). We distinguish roughly three groups of 'objects', which can occur in combination: informative documents, materials generated in the design process, and the built environment.

In the documents group, handbooks, norms and guidelines were appreciated for their ready-made solutions to requirements, embodying a tradition of know-how of the architectural profession. Research publications held a more difficult position, due to their misfit with the design process (an exception being the "little worlds" study (box 3 )). The main kind of materials for communicating experiential aspects, were professional publications. There was a common practice for architects to browse visual materials of other buildings. These could serve as a reference for the building type or materialisation. In the first case, architects studied how the programme was spatially organised, paying attention to the building layout and dimensions of spaces (cf. how it works). In the second case, architects focussed on the atmosphere, style and detailing of the building (cf. how it feels), which did not necessarily have the same programme, but could be designed by a favourite architect. The form (e.g., mainly pictures) and media (e.g., website) of the visual materials were however criticised for their marketing character and limited ability to communicate the building's full spatial experience (see also the remark by a partner at Canvas Architects in section 5.1).

A key document in the design process is the project definition. It serves as the main source of information and reference point about users in a project, and the degree to which it hints at the importance of attending to user experience can influence the design process (see Van der Linden, 
Dong, \& Heylighen, 2017). However, architects in our study remarked that the quality of briefing documents varied significantly, and criticized them for containing either too spatially determined requirements or too abstract concepts (e.g., in the residential care project (box 3), 'hominess', as requested in the brief, proved too abstract to work with until the architects encountered a personal narrative of a person with dementia). Whereas most briefs are highly technical, in a few exceptions additional documents provided a more human-centred focus (e.g., sketching portraits of residents).

A second group of objects entails materials generated during the design process, such as sketches, schemes, models, renders, collages, plans and elevations. As instruments, they enable architects to explore design moves and reflect on them, as such generating knowledge about the problemsolution at hand. The fact that we observed architects gesturing over models even when talking at the phone illustrates how pervasive this knowledge is. As records, these materials represent design ideas, codifying knowledge that can be shared with others. Plans and more technical details incorporate the solution resulting from a designerly inquiry process, and, to recycle this knowledge, their use as a basis in new projects was often promoted. However, as several architects indicated, even for professionals understanding the key was not self-evident, and knowledge got easily lost when they tried to interpret the (motivations behind) concepts in design materials without oral clarification.

Design materials are only to a limited extent introduced by clients and mainly come from the architects' sphere, but they play a vital role in the knowledge exchange between both. Client meetings function as the main arena for this knowledge exchange. Apart from architects' adoption of the client's narrative, we also observed a learning process in the other direction. Clients adopted architects' vocabulary, were instructed to read design conventions and were able to develop their question or vision in response to the architects' and proposals and questions. As expressions of architects' interpretations that can be iteratively assessed by clients in turn, design materials mediated between architects' and clients' spheres in discussions about use experience.

Third, buildings themselves also mediate knowledge about experience - in the most synthetic way. In discussions about the envisioned experience of a building in design, architects frequently referred to (aspects of) other buildings they knew (see, e.g., box 2). Whether concerning the project site, buildings with a similar programme or celebrated architecture, architects who 'have been there' are regarded as an authority (see section 5.2). Crucial to this knowing is having experienced the site/building oneself, which means that the own body is the instrument to interact with and evaluate the built environment. Whether positive or negative experiences, architects' next step is to try and unravel which architectural aspects contribute to them in order to work with these in the design at 
hand (see section 5.1). This brings us to the understanding that architects' expertise is intellectual as well as bodily, which makes it very personal.

In interactions with the client, the built environment can facilitate exchanging knowledge about user experience. Especially a joint visit of the client's current facility communicates more than what can be expressed in a briefing document. It provides architects with a contextual, embodied understanding of people's daily environment. As such, a joint visit provides an opportunity to not only unravel use issues but also collaboratively assess potential solutions in situ.

\section{Discussion}

\subsection{Designerly ways of knowing about users}

This article departed from the notion of architects' 'designerly ways of knowing' and explored what these entail with regard to user experience. Our findings resonate with related studies, which found that architects' construction of 'the user' is based on many sources, with a significant part of architects' knowledge being gained through personal or professional experience (e.g., previous projects) and informal methods (Kirkeby et al., 2015; Oygür, 2018). The observation that architects predominantly adopt informal knowledge strategies, may relate to the 'wicked' or ill-defined nature (cf. Rittel \& Webber, 1973) of design problems, making architects used to dealing with 'incomplete' information. In the usual absence of clear 'user needs', architects in our study tried to develop an implicit understanding of users' motivations to make the design problem manageable. This relates to Schön's (1988) analysis that designers are eager for information that can help construct a particular frame to set boundaries to the problem, which subsequently guides their attention, the use of other information, and the direction of design decisions towards a coherent solution.

Unpacking the notion of user experience in the context of architecture into perception, activity and meaning facets provides a lens for studying knowledge about users. Often we observed that architects took initiatives to explore users' perspectives in the domain of 'how a space works' (e.g., visiting reference projects (section 5.1), or recognising the need for insiders' perspectives (box 2)), but relied on their own experience to give shape to 'how a space feels' (e.g., through typical individual formal studies (box 1)). Initiatives to explore the motivation behind a question, on the other hand, were less self-evident but able to inform 'what a space means' (e.g., the ethnographic paper (box 3), and sleepover for those involved (section 5.2)), which can help making consistent design decisions across the facets. 
Another contribution of the study is that it offers insight into the personal character of knowledge about experience, which helps interpret the frequent observation that people are the dominant medium for knowledge transfer (e.g., Demian \& Fruchter, 2006). This personal character relates not only to how knowledge is registered (i.e., mainly in people), but also to how it is generated and applied. Architects' own body and understanding are fundamental to work with user experience. The body is an instrument to experience space and, together with one's value system, it provides input for assessing the adequacy of a design proposal. This has implications for interpersonal knowledge transfer, which necessarily involves making tangible these bodily and value-related aspects.

\subsection{Challenges and leads for knowledge transfer}

Architects experience difficulties in accessing the perspective and daily life of people who are very different or live in unfamiliar use contexts (Van der Linden, Dong, \& Heylighen, 2016b). Acquiring knowledge about use contexts is not enough, as its implicit nature makes this knowledge vulnerable to losing richness and meaning during knowledge transfer. Attention to the environment in which knowledge about user experience is mediated provides insight into different challenges and leads for knowledge transfer. This environment is essentially 'socio-material', meaning that knowledge is mediated by objects as well as people, supporting each other.

For instance, adequately shaping use opportunities in a building requires obtaining practical feedback from different stakeholders. However, architects experience difficulties in engaging in a dialogue with non-designers such as the client, who are often not used to reading design documents. In case architects gained insight through reference projects (see section 5.1) or current facility visits (see section 5.2), they experience difficulties in sharing this personal (often not documented) experience or research with the design team. There is a clear role for materials here, as a first lead, to overcome this challenge and support social interaction and make clients' and architects' knowledge tangible (e.g., see the concept drawing (box 3)). Whereas we observed diverse design materials now mainly being applied in individual explorations (see box 1 ), they have the potential to explicitly put aspects of user experience in front of team members and stakeholders to facilitate dialogues, hence mediating knowledge.

The other way around, the successful examples of narratives promoting architects' engagement with user experience show that social interaction also has the potential to support understanding the information that is recorded in objects. Tapping into the professional knowledge base (registered in persons, projects and even firms) turned out not to be that self-evident. Intangible values (e.g., 
personal or professional vision) might be difficult to express and pass on, whereas the distribution of tasks and knowledge (often pushed by limited resources) might engender diverging perspectives within design teams, heightening the risk of knowledge and engagement loss. This hampers consistency in thinking about user experience and shows a need for shared references within the team in order to exploit the available expertise. Narratives, as a second lead, have the potential to surpass their common, practical use, in terms of explaining how space is (to be) used (see box 2), but also to generate a holistic understanding, in terms of what meaning it (is to) convey(s) (see box 3 or section 5.2).

Recognition of the importance of embodied knowledge, in particular, seems to be key to advancing attention to users in design. Based on the observed mechanisms of design practice, we see potential in engaging with this embodied knowledge by coupling narratives to material aspects such as design materials and the built environment. Unlocking knowledge in a design-oriented way is expected to facilitate attending to user experience.

\subsection{Limitations of the study}

The timing of the study had both advantages and disadvantages. The fixed timeframe allowed to follow a varied sample of projects at different design stages. Yet unlike in a longitudinal study, we were unable to assess the impact of particular information sources on the design process - let alone on how the resulting buildings are used. As the limited timeframe allowed observing only a number of activities in real time, interviews and document analysis were helpful in co-constructing what happened before and in other projects. However, as supplemented information from the follow-up interview suggests, capturing a practice within such a limited frame cannot provide an exhaustive understanding of all the possible methods put in practice.

The intensive character of ethnographic studies set practical limitations to the number of firms that could be studied. However, the findings actually reflect more than the practices in the three firms as many participants represented years of experience in the architectural community. They were asked to reflect on parallels and differences in other firms they had worked in, and seemed to have a good overview of architectural practice due to the high rotation rate among and collaboration between firms. Still, findings cannot be generalised as practices might differ in other firms, but with the studied firms' descriptions in mind they can be transferrable to similar contexts.

As video- or audiotaping during observations was regarded too intrusive, a micro analysis of design practices and interactions was impossible. This was not deemed essential for gaining insight into the socio-material mediators of architects' knowing about users, but could have definitely enriched the 
findings (e.g., an analysis of architects' design moves and gestures when imagining users' perspectives in model making; conversational analysis of design meetings with clients).

\section{Conclusion}

This research aimed to understand architects' designerly ways of knowing about users in order to inform their practice. Through an ethnographic study it offered insight into how architects address (different facets of) user experience and how knowledge is mediated by the socio-material environment of design. As a complement to studies focussing on design cognition or on the ideal characteristics of (briefing) information, we unravelled practical preconditions set by the daily realities of architectural practice - where users are underrepresented and knowledge about their experience is hardly made explicit and largely based on assumptions and self-reference (Van der Linden, Dong, \& Heylighen, 2018). By unravelling the socio-material mediators that are at play, this study provides a concrete interpretation of Crilly, Maier and Clarkson's (2008) model representing the relationship between design intent and user experience, for the specific context of architectural design.

Attention to the role of implicit knowledge and informal ways of working defined our starting point to consider knowledge about user experience in its full complexity, and informing design practice as being more than making sources available. The holistic and situated approach of our study offered a more dynamic understanding of architects' knowing about users: it contributed to understanding how knowledge ends up in architects' knowledge base, but also that active efforts are needed to transfer this embedded knowledge within the network of design practice. Whereas some previous studies easily put aside implicit knowledge about user experience as something that is exchanged naturally in practice and focus on the easy-to-verbalise aspects (e.g., Kirkeby et al., 2015), our study suggests that the transfer of this implicit knowledge is also challenging. Moreover, the personal character of this knowledge makes it particularly vulnerable - as it can be lost, e.g., if people leave which raises the need for means to share and further develop it.

Paying attention to the socio-material mediators in the architectural design environment might be of relevance to promote knowledge transfer, by identifying leads to supporting architects' in addressing experience-related aspects in design. These leads are of interest both to researchers and clients who aim to inform architects' design process, as to architecture firms that want to consider their operation and advance their reflective practice. In order to bring into play bodily and valuerelated aspects, we highlight the importance of materialising narratives to make user experience tangible. In particular, there seemed an opportunity to work more with the meaning of space and 
tune ambitions by encouraging the dialogue between architects and clients. The next step of our research is looking into related design disciplines (e.g., product design), where several design techniques (e.g., scenarios) have been developed to explicitly work with user experience during design (Carroll, 2000). This study has led us to understand characteristics in architectural design practice that will help assess the potential of these techniques to support architects in designing human-centred environments.

\section{References}

Annemans, M., Van Audenhove, C., Vermolen, H., \& Heylighen, A. (2014). How to introduce experiential user data: The use of information in architects' design process. In Y.-K. Lim, K. Niedderer, J. Redström, E. Stolterman, \& A. Valtonen (Eds.), Proceedings of DRS 2014: Design's Big Debates (pp. 1626-1637). Umeå: Design Research Society.

Archer, B. (1979). Design as a discipline. Design Studies, 1(1), 17-20. https://doi.org/10.1016/0142$694 \times(79) 90023-1$

Badke-Schaub, P., \& Eris, O. (2014). A theoretical approach to intuition in design: Does design methodology need to account for unconscious processes? In A. Chakrabarti, \& L. Blessing (Eds.), An Anthology of Theories and Models of Design (pp. 353-370). London: Springer.

Bucciarelli, L. L. (1994). Designing Engineers. Cambridge, MA: MIT Press.

Carroll, J. M. (2000). Making Use: Scenario-based design of human-computer interactions. Cambridge, MA: MIT Press.

Crilly, N., Maier, A., \& Clarkson, P. J. (2008). Representing artefacts as media: Modelling the relationship between designer intent and consumer experience. International Journal of Design, 2(3), 15-27.

Cross, N. (1982). Designerly ways of knowing. Design Studies, 3(4), 221-227.

https://doi.org/10.1016/0142-694X(82)90040-0

Cross, N. (1999). Natural intelligence in design. Design Studies, 20(1), 25-39.

https://doi.org/10.1016/S0142-694X(98)00026-X

Cuff, D. (1992). Architecture: The story of practice. Cambridge, MA: MIT Press. 
Demian, P., \& Fruchter, R. (2006). An ethnographic study of design knowledge reuse in the architecture, engineering, and construction industry. Research in Engineering Design, 16(4), 184195. https://doi.org/10.1007/s00163-006-0010-x

Desmet, P. M. A. (2002). Designing Emotions. Delft: Technische Hogeschool Delft.

Diaz Moore, K., \& Geboy, L. (2010). The question of evidence: Current worldviews in environmental design research and practice. Architectural Research Quarterly, 14(2), 105-114.

https://doi.org/10.1017/\$1359135510000722

Ewenstein, B., \& Whyte, J. (2007). Beyond words: Aesthetic knowledge and knowing in organizations. Organization Studies, 28(5), 689-708. https://doi.org/10.1177/0170840607078080

Holl, S., Pallasmaa, J., \& Pérez-Gómez, A. (2006). Questions of Perception: Phenomenology of architecture. San Francisco, CA: William Stout.

Kasalı, A., \& Nersessian, N. J. (2015). Architects in interdisciplinary contexts: Representational practices in healthcare design. Design Studies, 41, Part B, 205-223.

https://doi.org/10.1016/j.destud.2015.09.001

Kirkeby, I. M. (2009). Knowledge in the making. Architectural Research Quarterly, 13(3-4), 307-313. https://doi.org/10.1017/\$1359135510000151

Kirkeby, I. M., Jensen, B. B., Larsen, K., \& Kural, R. (2015). Designing for health in school buildings: Between research and practice. Scandinavian Journal of Public Health, 43(3), 260-268.

https://doi.org/10.1177/1403494815569378

Krippendorff, K. (2006). The Semantic Turn: A new foundation for design. Boca Raton, FL: CRC Press.

Le Dantec, C. A. (2010). Situating design as social creation and cultural cognition. CoDesign, 6(4), 207-224. https://doi.org/10.1080/15710882.2010.527009

Luck, R. (2007). Using artefacts to mediate understanding in design conversations. Building Research \& Information, 35(1), 28-41. https://doi.org/10.1080/09613210600879949

Luck, R., \& McDonnell, J. (2006). Architect and user interaction: The spoken representation of form and function meaning in early design conversations. Design Studies, 27(2), 141-166.

https://doi.org/10.1016/j.destud.2005.09.001

McDonnell, J., \& Lloyd, P. (2014). Beyond specification: A study of architect and client interaction.

Design Studies, 35(4), 327-352. https://doi.org/10.1016/j.destud.2014.01.003 
McIntyre, L. J., \& Harrison, I. R. (2016). Knowledge exchange methods in practice: Knowing how to design for older adults. Architectural Research Quarterly, 20(3), 271-280.

https://doi.org/10.1017/S1359135516000361

Medway, P. (2000). Writing and design in architectural education. In P. Dias, \& A. Paré (Eds.), Transitions: Writing in academic and workplace settings (pp. 89-128). Cresskill, NJ: Hampton Press.

Murphy, K. M. (2005). Collaborative imagining: The interactive use of gestures, talk, and graphic representation in architectural practice. Semiotica, 2005(156), 113-145.

https://doi.org/10.1515/semi.2005.2005.156.113

Newcombe, R. (2003). From client to project stakeholders: A stakeholder mapping approach.

Construction Management and Economics, 21(8), 841-848.

https://doi.org/10.1080/0144619032000072137

Niedderer, K. (2007). Mapping the meaning of knowledge in design research. Design Research Quarterly, 2(2), 1-13.

Norman, D. A. (2004). Emotional Design: Why we love (or hate) everyday thing. New York, NY: Basic Books.

Oygür, I. (2014). Transforming user information into user knowledge: A multiple case study. In Y.-K. Lim, K. Niedderer, J. Redström, E. Stolterman, \& A. Valtonen (Eds.), Proceedings of DRS 2014:

Design's Big Debates (pp. 360-373). Umeå: Design Research Society.

Oygür, I. (2018). The machineries of user knowledge production. Design Studies, 54, 23-49.

https://doi.org/10.1016/j.destud.2017.10.002

Rittel, H., \& Webber, M. (1973). Dilemmas in a general theory of planning. Policy Sciences, 4(2), 158167. https://doi.org/10.1007/BF01405730

Schmidt, R., \& Dainty, A. (2015). The influence of practice culture on designed artefacts. Architectural Research Quarterly, 19(4), 397-409. https://doi.org/10.1017/\$1359135516000051

Schön, D. A. (1983). The Reflective Practitioner: How professionals think in action. New York, NY: Basic Books.

Schön, D. A. (1988). Designing: Rules, types and words. Design Studies, 9(3), 181-190.

https://doi.org/10.1016/0142-694X(88)90047-6

Sismondo, S. (2004). An Introduction to Science and Technology Studies. Malden, MA: Blackwell. 
Stolterman, E. (2008). The nature of design practice and implications for interaction design research. International Journal of Design, 2(1), 55-65.

Styhre, A. (2011). The architect's gaze: The maintenance of collective professional vision in the work of the architect. Culture and Organization, 17(4), 253-269.

https://doi.org/10.1080/14759551.2011.590304

Van der Linden, V., Dong, H., \& Heylighen, A. (2016a). Capturing architects' designerly ways of knowing about users: Exploring an ethnographic research approach. In P. Lloyd \& E. Bohemia (Eds.), Proceedings of DRS2016: Design + Research + Society - Future-Focused Thinking (Vol. 8, pp. 32293243). Brighton: Design Research Society.

Van der Linden, V., Dong, H., \& Heylighen, A. (2016b). From accessibility to experience: Opportunities for inclusive design in architectural practice. Nordic Journal of Architectural Research, 28(2), 33-58.

Van der Linden, V., Dong, H., \& Heylighen, A. (2017). The good client: How architect-client dynamics mediate attention to users. In R. Hay \& F. Samuel (Eds.), Professional Practices in the Built Environment (pp. 174-183). Reading: University of Reading.

Van der Linden, V., Dong, H., \& Heylighen, A. (2018). Architects' attitudes towards users: A spectrum of advocating and envisioning future use(rs) in design. ARDETH, (2), 197-216.

https://doi.org/10.17454/ARDETH02.12

Van der Linden, V., Van Steenwinkel, I., Dong, H., \& Heylighen, A. (2016). Designing "little worlds" in Walnut Park: How architects adopted an ethnographic case study on living with dementia. In P. Lloyd \& E. Bohemia (Eds.), Proceedings of DRS2016: Design + Research + Society - Future-Focused Thinking (Vol. 8, pp. 3199-3212). Brighton: Design Research Society.

Vaes, K. (2014). Product stigmaticity: Understanding, measuring and managing product-related stigma (PhD Dissertation). TU Delft, Delft.

Yaneva, A. (2009). The Making of a Building: A pragmatist approach to architecture. Bern: Peter Lang.

Yaneva, A. (2018). New voices in architectural ethnography [Editorial]. ARDETH, (2), 17-32. https://doi.org/10.17454/ARDETH02.03

Zeisel, J. (1984). Inquiry by Design: Tools for environment-behaviour research. Cambridge: Cambridge University Press. 


\section{Acknowledgements}

The authors would like to thank the participants for granting access to their daily professional environment and for the time and effort devoted to explaining their work, motivations and concerns. This work was supported by the KU Leuven Research Fund; and through a PhD Fellowship of the Research Foundation - Flanders (FWO). 